\title{
Enzyme measurements for risk evaluations in sewage treatment plants
}

\author{
Ragnar Rylander ${ }^{1^{*}}$, Anna Calo ${ }^{2}$ \\ ${ }^{1}$ BioFact Environmental Health Research Center, Lerum, Sweden; ${ }^{*}$ Corresponding Author: envhealth@biofact.se \\ ${ }^{2}$ Study Consultancy Inc., Örebro, Sweden
}

Received 9 February 2012; revised 18 March 2012; accepted 16 April 2012

\begin{abstract}
Objectives: Work in sewage treatment plants may cause health problems in terms of airways symptoms, unusual tiredness, fever, and diarrhoea. The presence of such symptoms has been related to bacterial endotoxin. The project was undertaken to assess if risk evaluations could be performed by measuring the amounts of two different microbial enzymes and to evaluate their relation to endotoxin. Methods: Measurements were performed at 120 work sites in 10 different sewage treatment plants of varying age and capacity. The content of $\mathrm{N}$-acetylhexosaminidase (NAHA), bacterial hydrolase (BH) and endotoxin was measured in sewage water and in airborne samples. Results: There was a close relationship between endotoxin and NAHA, both in the water itself and in air samples. Generally exposure levels were low but higher at work sites where the water or sludge was agitated or when repairing pumps and cleaning basins. Conclusions: Measurements of NAHA are suitable to determine risk exposures in sewage treatment plants. Such measurements are faster and cheaper than measures of endotoxin. A level of $50-70 \mathrm{U} / \mathrm{m}^{3}$ is suggested as a risk threshold. Further work is required to define more precise threshold limit values.
\end{abstract}

Keywords: Sewage Water; Enzyme; $\mathrm{N}$-Acetyhexosaminidase; Hydrolase; Inhalation

\section{INTRODUCTION}

Sewage treatment plants represent a growing industry in view of environmental and sanitary requirements in modern society. The sewage pipes on Crete 2500 years B.C. reflects a knowledge that has not been applied on a large scale in Western society till the $19^{\text {th }}$ century. Sewage water contains effluents from industry, households, and draining of surfaces such as roads and parks. During treatment the water is transported to different basins, aerated and treated with chemicals. Employees in the plants are exposed by contact or by inhaling aerosols of the sewage water and its different components such as sludge.

Numerous reports have documented the presence of occupationally related medical effects among workers in sewage treatment plants [1-6]. There is an increased incidence of symptoms of respiratory and skin irritation, excessive fatigue, muscle and joint pains, flue-like symptoms (toxic pneumonitis), and diarrhoea. Objective measures report decreased pulmonary function and increased levels of C-reactive protein in blood and interleukin-8 in nasal lavage as indicators of an inflammatory process. Methods to estimate the exposure are thus important for preventive and worker education purposes.

Sewage water contains a mixture of a large number of microorganisms, bacteria, fungi, and protozoa [7-9]. A major part of the microbial contamination stems from drainage water from surfaces, comprising a large variety of fungal species and bacteria. There is also a substantial portion of bacteria and viruses from the human intestinal tract. It is likely that a large part of the symptoms reported from employees in sewage plants are caused by this microbial exposure and in particular endotoxin from Gram-negative bacteria, in view of the inflammagenic potential of this agent [10]. Gastrointestinal viruses have also been suggested as a causative agent for the gastrointestinal symptoms [11] and tiredness could be caused by exposure to hydrogen sulphur, a well know toxic agent present in sewage treatment plants.

For a risk assessment in sewage treatment plants, measurements of the amount of airborne endotoxin have been done in several studies $[5,12,13]$. Reported exposure levels range from a few up to $270 \mathrm{ng} / \mathrm{m}^{3}$. Particularly high levels were present at work sites where the water was agitated, in enclosed spaces such as pump pits, or when servicing machinery using high pressure water hosing. Endotoxin has been analysed using the Limulus test which is highly specific for endotoxin and sensitive 
in the order of picograms/mL. There is, however, an important inter-laboratory variation, which is a main reason why no occupational exposure standard has been implicated [14]. The analysis technique is also laborious and quite expensive.

In view of the large number of biologically active agents-bacteria, viruses, proozoa, and fungi-risk assessments based on measurements of each of these agents is not feasible from a practical point of view. An alternative would be to indentify an agent that is easy to measure and which relates to the presence of other agents as an index of toxicity. The final evaluation of such measurements can be done by comparing the results with those for an agent with a known biological affect. As the aerosol from sewage water contains microorganisms and fungi, a possiblity to assess the exposure could be to determine components present in the cell wall of these, such as enzymes. Previous studies have shown that $\mathrm{N}$-acetylhexosaminidase (NAHA) relates to fungal biomass, both in the growth and stationary phase [15]. Significant correlations between NAHA and total spore counts were found in air samples and in dust generated from biomass in a biofuel plant [16]. A close relation between airborne NAHA values and the presence of fungi in buildings has been reported [17]. These studies demonstrate that NAHA can be used as a marker for mould cell biomass exposure. The bacterial contamination has also been assessed using the bacterial enzyme hydrolase $(\mathrm{BH})$ although no extensive environmental measures have been published.

To explore the usefulness of enzyme measurements for risk assessment in sewage treatment plants, measurements were performed at different work sites. The exposure was determined by measuring the amount of airborne endotoxin, NAHA, and $\mathrm{BH}$. In addition, calculations were made of the relationships between the three parameters and the reproducibility of the methods.

\section{MATERIAL AND METHODS}

\subsection{Sampling}

The investigation was performed in 10 ad hoc selected sewage treatment plants of various sizes and ages in Sweden over a period of 14 months.

Samples of the water in the plants were taken from different basins. Air samples ( 300 L/min) were taken at different work sites using a filter (Mixed Cellulose Esters, $25 \mathrm{~mm}$ PCM Cassettes, $0.8 \mu \mathrm{m}$ pore size, Zefon International, Inc., Ocala, FL, USA) and a high capacity pump (10 - 20 L/min, Gardner Denver VTF 3, USA).

The different work sites, where air sampling was performed, were classified according to the degree of agitation of the sewage water. The degree of agitation varied between the plants depending on the technical equipment etc and the same site, such as the inlet, could have different agitation grades in different plants. The agitation was thus judged according to a subjective assessment by the same person at the particular site into three classes, 1 = little agitation, 2 = moderate agitation, and $3=$ strong agitation.

\subsection{Analysis}

To analyze enzymes in the water samples, $100 \mu \mathrm{L}$ of water was added to one $\mathrm{mL}$ of substrate for the bacterial enzyme hydrolase $(\mathrm{BH})$ (BactiQuant, Mycometer A/S, Copenhagen, Denmark), or to one $\mathrm{mL}$ of a fluorogenic enzyme substrate (4-methylumbelliferyl N-acetyl-betaD-glucosaminide, Mycometer A/S, Copenhagen, Denmark) to determine the enzyme $\mathrm{N}$-acetylhexosaminidase (NAHA). After a reaction time that was determined by the room temperature, usually around 30 minutes, the liquid was placed in a cuvette together with $2 \mathrm{~mL}$ of an alkaline buffer (the developer). The fluorescence in the sample was read in a fluorometer (Turner Designs, Sunnyvale, CA, USA). The value read in the fluorometer was divided by 10 and rounded off to the nearest, whole number, to minimise random scatter due to methodological variations, and expressed as units (U).

To analyse the filters, the enzyme substrates were added directly to the filter in the sampling cassette and incubated for around 30 minutes, depending upon room temperature. Thereafter $2 \mathrm{~mL}$ of the developer was added to the filter and the liquid in the filter holder was sucked out through the filter and collected in a cuvette. The fluorescence of this fluid was read as described above.

To analyse for endotoxin an automatic analyser based on the activity of the Limulus lysate was used (Endosafe PTS, Charles River. Charleston SC, USA). The water samples were diluted in endotoxin free water. For the air filters two $\mathrm{mL}$ of endotoxin free water was added to the filter, sucked out trough the filter and diluted in endotoxin free water. After appropriate dilutions, $4 \times 25 \mu \mathrm{L}$ of the samples were placed in a cartridge containing reference endotoxin, and read in an automatic spectrophotometer as endotoxin units (EU - 10 EU corresponds to about one nanogram endotoxin).

\subsection{Statistical Analysis}

Differences between groups were assessed using the Mann-Whitney test and relations between variables using the Spearman correlation. A p-value of 0.05 was considered significant.

\section{RESULTS}

\subsection{Sewage Water Samples}

Sewage water was analysed 10 times with $\mathrm{BH}$ and 
NAHA in two separate tests. The results are shown in Table 1.

The amount of $\mathrm{BH}$ was higher than that of NAHA. The variation between repeat measures was higher for $\mathrm{BH}$ than for NAHA. A smaller number of repetitive tests was done for endotoxin $(n=5$, mean 7020 EU/mL, SEM $=145$ ). This shows that the variation between repeated measures was relatively small also for endotoxin.

Endotoxin, BH, and NAHA were analysed on two occasions in 7 - 10 different water samples. There was a significant relationship between NAHA and endotoxin (corr coeff $=0.694, p=0.002$ ) and between NAHA and $\mathrm{BH}$ (corr coeff $=0.579, \mathrm{p}=0.007$ ). There was no relationship between $\mathrm{BH}$ and endotoxin.

The relation between endotoxin and NAHA in 17 water samples is illustrated in Figure 1.

There was a close relation between the amounts of NAHA and endotoxin.

\subsection{Air Samples}

Table 2 shows the results from repeated measurements of NAHA and $\mathrm{BH}$ at the same work site.

The variation between repeated measures was considerably higher for $\mathrm{BH}$.

The results from the parallel sampling of endotoxin

Table 1. NAHA and BH (U/mL) in two tests with 10 analyses of the same sewage water. Arithmetic mean and standard error of the mean (SEM).

\begin{tabular}{ccc}
\hline Enzyme & NAHA & BH \\
\hline Test 1 & 749 & \\
Mean & 8 & 94 \\
SEM & & \\
Test 2 & 2085 & 8619 \\
Mean & 1308 & 6040 \\
SEM & & \\
\hline
\end{tabular}

Table 2. NAHA and BH $\left(\mathrm{U} / \mathrm{m}^{3}\right)$ in two experiments with 10 analyses of airborne sampling at the same work site. Arithmetic mean and standard error of the mean (SEM).

\begin{tabular}{ccc}
\hline Enzyme & NAHA & BH \\
\hline Sludge press & 222 & 954 \\
Mean & 14 & 393 \\
SEM & & \\
Sludge loading & 149 & 173 \\
Mean & 18 & 99 \\
SEM & &
\end{tabular}

and NAHA at different work sites are illustrated in Figure 2.

Similarly to the water samples, a strong relationship was found between the amounts of NAHA and endotoxin. Parallel measures of endotoxin and BQ were not performed.

The results from measurements in relation to the degree of agitation are shown in Table 3.

With increasing agitation the amounts of endotoxin, $\mathrm{BH}$, and NAHA increased. There was a significant relationship between the amounts of NAHA and the degree of agitation (corr coeff 0.800, p $<0.001$ ), and between $\mathrm{BH}$ and degree of agitation (corr coeff 0.657, $\mathrm{p}<0.001$ ). The variations in values for $\mathrm{BH}$ were larger than for the other parameters, particularly at the highest degree of agitation.

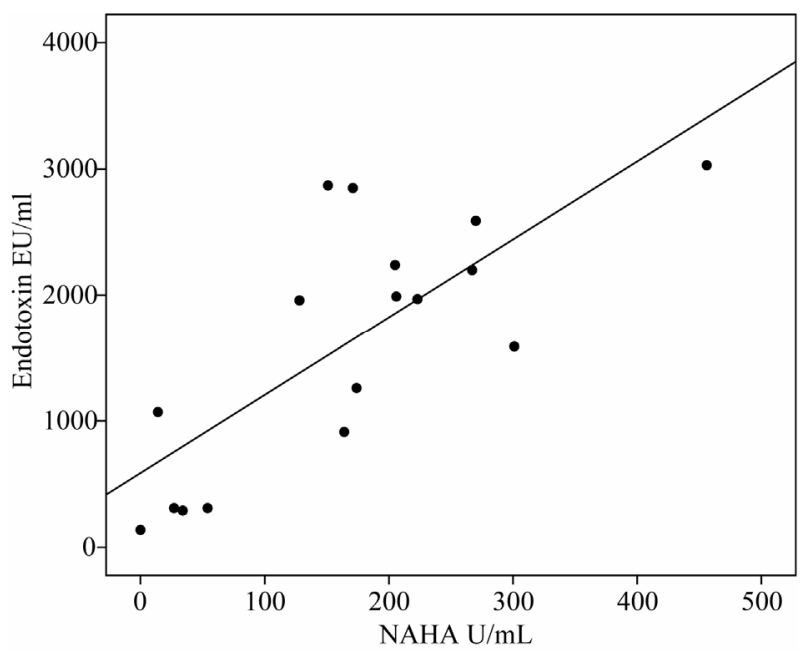

Figure 1. The relation between the amount of endotoxin and NAHA in different samples of sewage water (corr coeff = 0.694, $\mathrm{p}=0.002$ ).

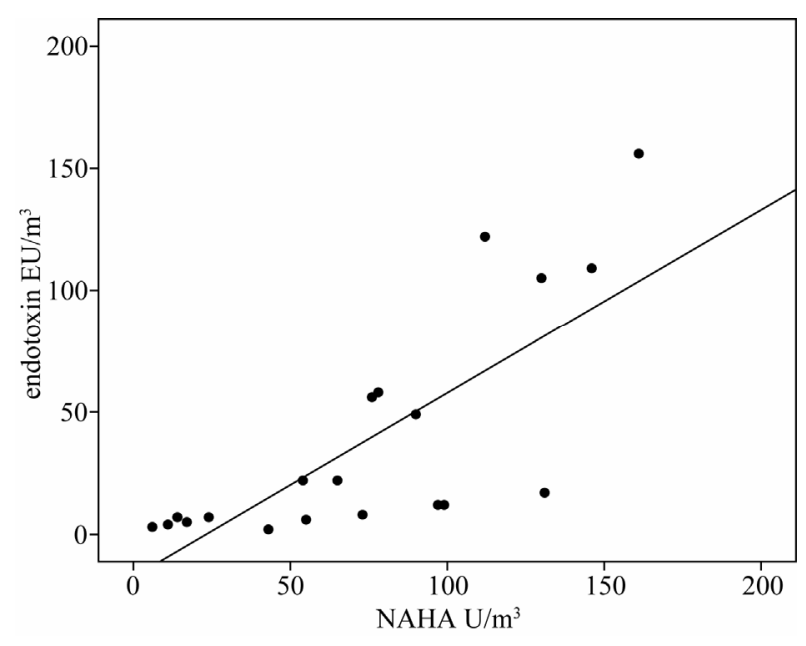

Figure 2. The relation between NAHA and endotoxin in airborne samples at different work sites (corr coeff 0.844, p < 0.001). 
Table 3. Airborne endotoxin $\left(\mathrm{EU} / \mathrm{m}^{3}\right), \mathrm{BH}$ and NAHA $\left(\mathrm{U} / \mathrm{m}^{3}\right)$ at work sites with different degrees of agitation. $\mathrm{n}=$ number of measurements, mean values and standard error of the mean.

\begin{tabular}{lcccccc}
\hline Agitation & $\mathbf{n}$ & Endotoxin & $\mathbf{n}$ & BH & $\mathbf{n}$ & NAHA \\
\hline low & 4 & $10.3(1.3)$ & 14 & $12.2(9.1)$ & 19 & $3.4(1.3)$ \\
moderate & 6 & $9.3(2.7)$ & 34 & $25.3(8.8)$ & 43 & $17.0(2.9)$ \\
high & 16 & $48.7(12.7)$ & 20 & $1179(657)$ & 56 & $132(27.3)$ \\
\hline
\end{tabular}

\section{COMMENTS}

\subsection{Methods}

The results demonstrate that sewage water contains the enzymes hydrolase (BH), N-acetylhexosaminidase (NAHA), and endotoxin. This is expected in view of the sources of sewage water as discussed in the introduction.

There are some shortcomings in the study. The number of measurements at different work sites was not equal because of practical reasons. For endotoxin, the number of samples sites was lower, mainly due to the high prize of the reagents for the analysis. In spite of these shortcomings, the results for the different groups were quite uniform and consistent.

Regarding the two enzymes measured, $\mathrm{BH}$ showed a variability in results at the different measuring sites which was larger than for NAHA and endotoxin. This suggests that the enzyme is influenced by the sampling conditions. Desiccation when a large volume of air is drawn through a filter is known to affect the viability of bacteria and a similar process could be envisioned regarding BH. Furthermore it has previously been shown that a decrease in $\mathrm{BH}$ activity takes place within days of storage of the filters. The NAHA values had a smaller variation and experience from an earlier study shows that the filters can be stored for a few weeks without loss of activity [17]. Against this, it was concluded that the $\mathrm{BH}$ method is not suitable for risk assessment determinations.

\subsection{Risk Assessment}

The experience from the study shows that exposure to high levels of NAHA and endotoxin is relatively uncommon during normal operations in modern sewage water treatment plants. This is in agreement with the results from earlier studies in Sweden and the Netherlands $[11,18]$. The amounts are usually higher at work sites where the water is agitated and when cleaning pumps or spraying in basins. In general it is thus sufficient to determine the presence of risk by judging the degree of agitation at a particular work site.

There was a relation between endotoxin and NAHA, both for water and air samples. A higher amount of NAHA implies a higher exposure to endotoxin. Measurements of NAHA can thus be used to describe the risk of development of medical symptoms in connection with exposure to sewage water. Measurements of NAHA can also be used to evaluate the effects of different technical alterations, and to demonstrate for employees the work sites where a risk is present, thus motivating them to carry respiratory protection.

It is not within the scope of the present study to suggest maximum exposure values. This would require a larger material and medical investigations. Some information can, however, be obtained by comparing the relation between endotoxin and NAHA found in this investtigation with previous studies on endotoxin. A suggestion for a maximum value for endotoxin at $50 \mathrm{EU} / \mathrm{m}^{3}$ has been presented by The National Health Council in the Netherlands [19]. Using the dose-response relationship shown in Figure 2, a maximum value of 50 - 70 NAHA would avoid the risk of endotoxin exposures in excess of 50 EU. Further work is needed to ascertain a more precise maximum NAHA value.

The duration of the exposure is another important parameter for exposure limitation. Experience from inhalation experiments with pure endotoxin and information from employees at sewage treatment plants demonstrate that effects may appear after a relatively short exposure [20]. A maximum exposure duration of 15 minutes thus seems reasonable.

\section{CONCLUSION}

The level of the enzyme N-acetylhexosaminidase (NAHA) can be used as a measure of risk during work at sewage treatment plants. The analysis technique is easy, the results reproducible and the cost considerably lower that an analysis of endotoxin. Additional investigations are required but available data suggest that an exposure level exceeding $50-70 \mathrm{U} / \mathrm{m}^{3}$ and a duration exceeding 15 minutes may implicate a risk of medical effects.

\section{ACKNOWLEDGEMENTS}

The study was funded by Svenskt Vatten, Sweden, and Kumla municipality, Sweden.

\section{REFERENCES}

[1] Anders, W. (1954) Die berliner kanalbetriebsarbeiter. 
Medical Microbiology and Immunology, 139, 341-371. doi:10.1007/BF02152578

[2] Mattsby, I. and Rylander, R. (1978) Clinical and immunological findings in workers exposed to sewage dust. Journal of Occupational and Environmental Medicine, 20, 690-692.

[3] Nethercott, J.R. and Holness, D.L. (1988) Health status of a group of sewage treatment workers in Toronto, Canada. American Industrial Hygiene Association Journal, 49, 346-350. doi:10.1080/15298668891379873

[4] Rylander, R. (1999) Health effects among workers in sewage treatment plants. Occupational and Environmental Medicine, 56, 354-357. doi:10.1136/oem.56.5.354

[5] Thorn, J., Beijer, L. and Rylander, R. (2002) Work-related symptoms among sewage workers, a nationwide survey in Sweden. Occupational and Environmental, 59, 562-566. doi:10.1136/oem.59.8.562

[6] Heidal, K.K., Madsö, L., Huser, P.O., et al. (2010) Exposure, symptoms and airway inflammation among sewage workers. Annals of Agricultural and Environmental Medicine, 17, 263-268.

[7] Laitinen, S., Kangas, J., Kotimaa, M., et al. (1994) Workers' exposure to airborne bacteria and endotoxin at industrial wastewater treatment plants. American Industrial Hygiene Association Journal, 55, 1055-1060. doi:10.1080/15428119491018330

[8] Pražmo, Z., Krysinska-Traczyk, E., Skórska, C., et al. (2003) Exposure to bioaerosols in a municipal sewage treatment plant. Annals of Agricultural and Environmental Medicine, 10, 241-248.

[9] Korzeniewska, E. (2011) Emission of bacteria and fungi in the air from wastewater treatment plants-A review. Frontiers in Bioscience, 3, 393-407. doi:10.2741/s159

[10] Rylander, R. (2007) Endotoxin in the air-Good or bad for you? Clinical Pulmonary Medicine, 14, 140-147. doi:10.1097/CPM.0b013e3180557041

[11] Thorn, J. and Beijer, L. (2004) Work-related symptoms and inflammation among sewage plant operatives. International Journal of Occupational and Environmental
Health, 10, 84-89.

[12] Thorn, J., Beijer, L., Jonsson, T., et al. (2002) Measurements strategies for the determination of airborne bacterial endotoxin in sewage treatment plants. Annals of Occupational Hygiene, 46, 549-554. doi:10.1093/annhyg/mef068

[13] Smit, L.A.M., Spaan, S. and Heederik, D. (2005) Endotoxin exposure and symptoms in wastewater treatment workers. American Journal of Industrial Medicine, 48, 30-39. doi:10.1002/ajim.20176

[14] Chun, D.T.W., Chew, V., Bartlett, K., et al. (2002) Second inter-laboratory study comparing endotoxin assay results from cotton dust. Annals of Agricultural and Environmental Medicine, 9, 49-53.

[15] Miller, M., Palojärvi, A., Rangger, A. Reeslev, M. and Kjöller, A. (1998) The use of fluorogenic substrates to measure fungal presence and activity in soil. Applied and Environmental Microbiology, 64, 613-617.

[16] Madsen, A.M. (2003) NAGase activity in airborne biomass dust and relationship between NAGase concentration and fungal spores. Aerobiologia, 19, 97-105. doi:10.1023/A:1024401523656

[17] Rylander, R., Reeslev, M. and Hulander, T. (2010) Airborne enzyme measurements to detect indoor mould exposure. Journal of Environmental Monitoring, 12, 21612164. doi:10.1039/c0em00336k

[18] Douwes, J., Mannetje, A. and Heederik, D. (2001) Workrelated symptoms in sewage treatment workers. Annals of Agricultural and Environmental Medicine, 8, 39-45.

[19] Liebers, V., Brüning, T., Raulf-Heimsoth, M. (2006) Occupational endotoxin-exposure and possible health effects on humans. American Journal of Industrial Medicine, 49, 474-491. doi:10.1002/ajim.20310

[20] Sandström, T., Bjermer, L. and Rylander, R. (1992) Lipopolysaccharide (LPS) inhalation in healthy subjects increases neutrophils, lymphocytes and fibronectin levels in bronchoalveolar lavage fluid. European Respiratory Journal, 5, 992-996. 